ESJ Social Sciences

\title{
Why Are Arabic Adult Learners in Kuwait Afraid of Making Mistakes in Their English Classroom?
}

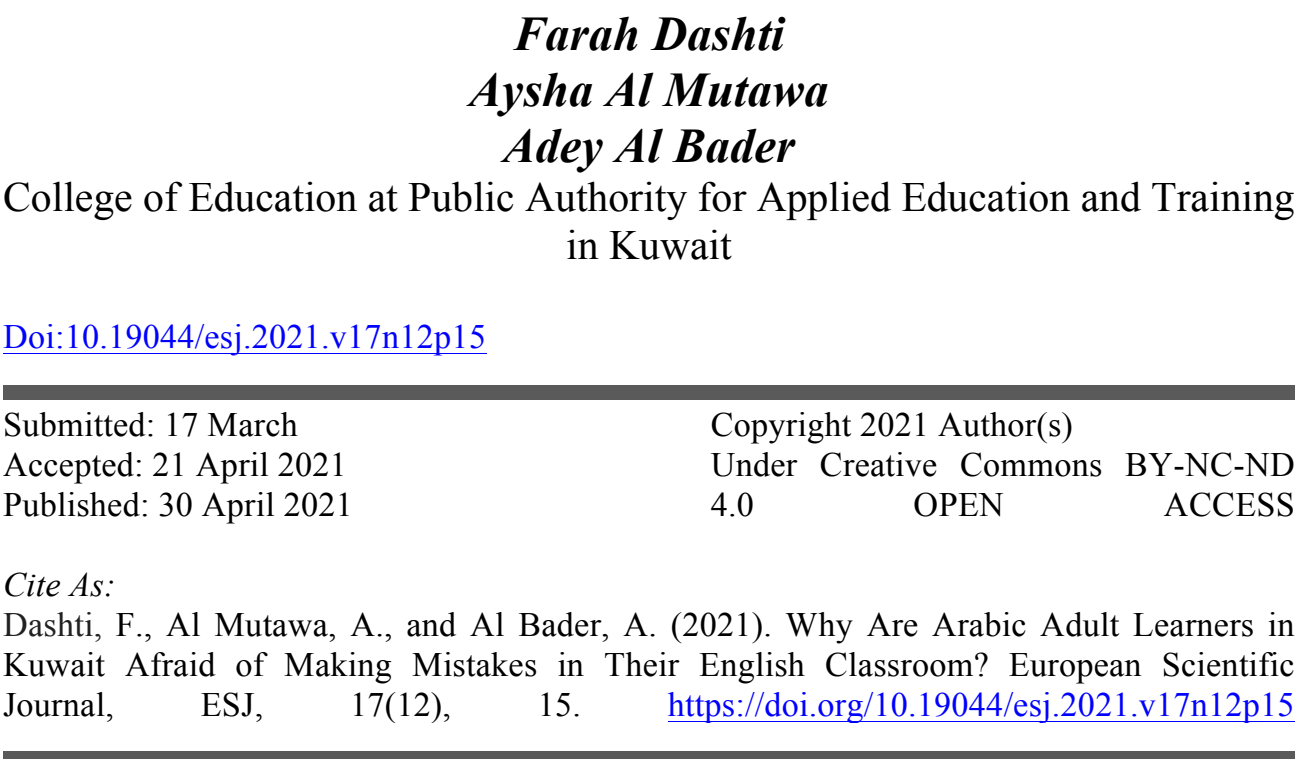

Abstract

The English language is a second language in Kuwait, and English has been added to the school curriculum with the aim that when students graduate, they will be bilingual in Arabic and English. However, although Arabic adult learners graduate to be fluent in their first language, they struggle in English. This paradox led us to consider specific factors that may inhibit Arabic adult learners from becoming proficient in English when they graduate from high school. One such factor is an unwillingness to speak English in the classroom. The focus of this study, therefore, is to investigate fear of making mistakes as one of factors underlying this unwillingness. Since the study was created during the pandemic, classes in Kuwait, at the time, were taught online only. A questionnaire was given to 210 female Arabic native speakers taking the English foundation course at the College of Basic Education at the Public Authority for Applied Education and Training. The questionnaire focused on factors that might induce a fear of making mistakes when speaking English in the classroom. The results of the study indicated that the most significant factor in this regard was students' previous experience with English teachers who ridiculed them when they made mistakes in their classes. The findings suggest that when teachers do 
not take the appropriate approach to motivate students when they make mistakes, this can negatively affect the student's language learning process.

Keywords: Adult Learners, English classroom

\section{Introduction}

It is generally accepted that learning a second language at a young age is easier than learning when you are an adult. Children can pick up the mechanisms of a language without someone teaching them directly. Because they have not yet developed the concept of inhibition, children continuously attempt to speak a language without worrying about other factors that may impede them from practicing (Brown, 2007). They do not build up a set of defence mechanisms to protect their ego because they have not yet developed the idea of self. With adults, on the other hand, their ego has built up strategies to protect them from several variables and factors.

According to Tuan and Mai (2015), the factors that impede adult language learning include lack of confidence and pressure to perform well. Furthermore, if adults lack vocabulary, they find it "difficult to get meaning or understand the conversations, and keep the interaction going" (Wahidah, 2016). Children, in contrast, are fearless when it comes to making verbal mistakes due to their lack of self-awareness.

A further significant issue is age. According to Stephen Krashen (1973), the critical period for a child to learn a second language is from early childhood up to the age of five. This critical period for language acquisition is measured by the development of brain lateralization, which is "established well before puberty" (Krashen, 1973). Therefore, if a child is exposed to a second language before the age of five, they will be more likely to achieve native speaker competence.

When adults are learning English as a second language, they face difficulties with the idea of making verbal mistakes in front of their classmates and teacher, even though they know that "making mistakes is the first step of learning" (Ajmi, 2021). They face an intricate web of factors, both internal and external, that hinder them from sharing their answers or opinions in a classroom.

The internal factors that students learning a second language must deal with and that interfere with a student's learning process might be "one of the most important influences on language learning success or failures" (Oxford, 1990). These factors can range from language anxiety, emotions and self-doubt, to lack of motivation (Brown, 2007). In Kuwait, Arabic 
speakers learning English face the same challenges; however, they may face additional obstacles engendered by instructors' behaviour and classroom environment (Halimi, Daniel, \& Alshammari, 2020). Furthermore, teachers focus on grammar skills and create a sense of discouragement, a feeling that English is a complicated language, and thus, there is a lack of motivation (Rashed, 2017).

Further factors that have an influence on Arabic native speakers' lack of success in speaking English proficiently are incorrect pronunciation, lack of practice outside the classroom, lack of English vocabulary knowledge, mother tongue interference, age, attitudes arising from earlier instructional experiences, attitude towards the English language, and motivation (Benraghda, Radzuan, \& Benrraghda, 2017).

When it comes to teaching and learning English, all four skills are essential: reading, speaking, listening, and writing. According to Dashti (2018), the English skills of students at the College of Basic Education at PAAET are below average, and are "absolutely unsatisfying, and hence, do not meet the real needs of the prospective EFL teachers." Students at the College of Basic Education do not practice speaking or listening to English outside of the classroom (Al Darwish \& Sadeqi, 2016). These two skills usually represent the introductory steps in learning any new language. A person that wants to learn a second language often begins by listening to someone speak it, then they attempt to practice speaking it themselves. Listening therefore plays a very important role in developing one's speaking ability (Shumin, 2012). Development of these two skills would then lead to reading and writing in the foreign language. All four learning skills are intertwined with one another.

Against this background the important question is, why are students not motivated to learn English, and what might be the reasons for their lack of willingness to communicate (WTC)?

Willingness to communicate is the intention to initiate communication. WTC is based on the notion, first introduced by Burgoon (1976), of unwillingness to communicate in the first language. McCroskey and Baer (1985) adapted this to willingness to communicate in the first language. They "conceptualized WTC as the probability of engaging in communication when free to choose to do so" (MacIntyre, Clement, Dornyei, \& Noels, 1998). They posited "communication competence, communication apprehension, self-esteem and cultural diversity as antecedents of WTC" (Bukhari, Cheng, \& Khan, 2015). In 1998, WTC was applied to second language learners by MacIntyre and Charos, who proposed a pyramid with six layers. The bottom three layers (IV, V AND VI) focused on 'situational influences' such as motivational propensities, affective-cognitive context, and social and individual context (MacIntyre, 
Clement, Dornyei, \& Noels, 1998). The top three layers (I, II and III) include 'enduring influences', which are communication behaviour, behaviour intention, and situated antecedents, as seen in Figure 1.

\section{Figure 1}

MacIntyre et al.'s Model of Willingness to Communicate

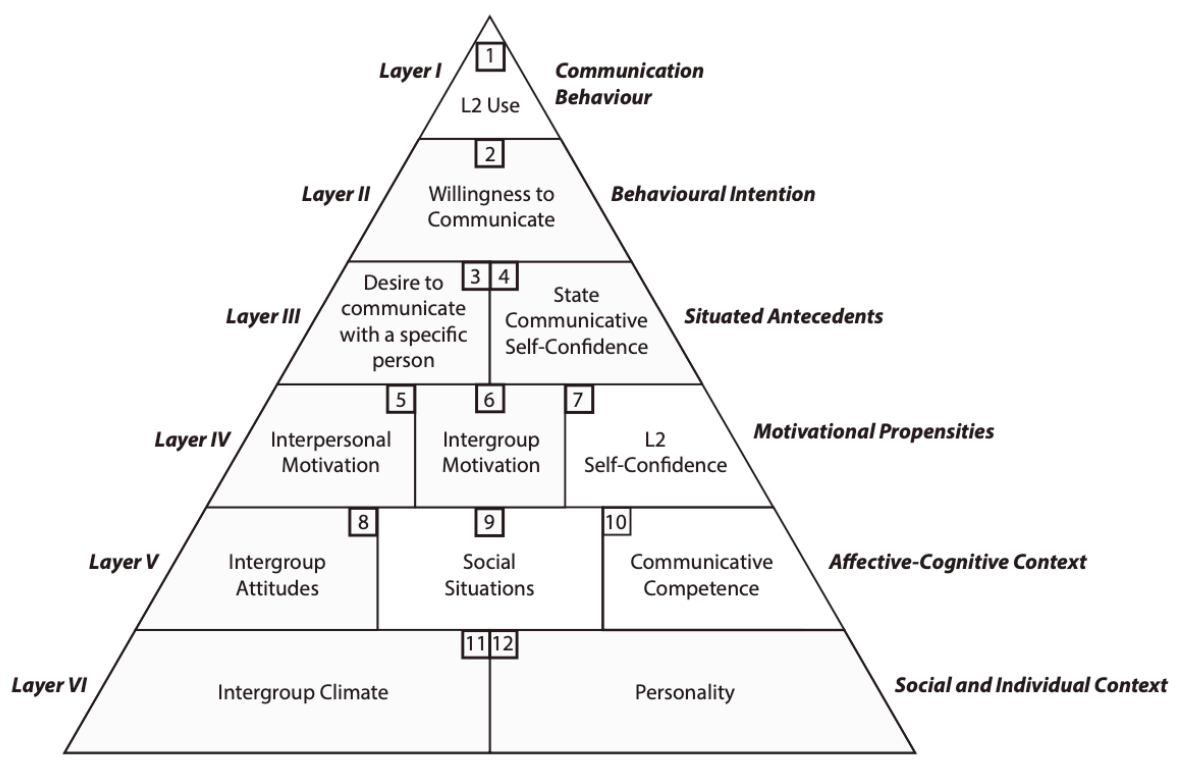

Little research has been done on WTC in the Gulf Arab region (Bukhari, Cheng, \& Khan, 2015), and we are of the opinion that this presents a gap in literature that needs to be filled. This led us to investigate how fear of making mistakes might inhibit CBE pre-service teachers from practicing spoken English in their ESL classes.

\section{Background}

\subsection{The Importance of the English Language in Kuwait}

Kuwait is a small country that is centrally located on a commercial trade route. As a result, "Kuwait was compelled to use English to facilitate merchants' operations" (Al-Nouri, 2019). In addition, the oil production industry led to job opportunities for foreigners to work in Kuwait. Since English was the common language that all of the employees spoke, it became an essential language for Kuwaitis that worked in the oil industry. English thus gained importance in Kuwait's financial and economic growth.

Kuwait is divided into five governates: Asma, Hawalli, Mubarak Alkabeer, Ahmedi, and Fahaheel, each of which adheres to rules of the Ministry of Educations (MoE). Arabic is the native language, and English is 
considered to be a second language. As of 1993, English has been added to the public school's curriculum as a mandatory course, and when learners graduate from school, they will have taken English classes for 12 years.

\section{Influences of Region and Religion on Adult Learning The English Language}

Arabic is the native and primary language spoken in Kuwait due to the region and culture revolving around Islam and it's beliefs, as well as being heavily intertwined with the Qur'an. Being that the constitution of Kuwait deemed Islam as the basis of legislation, most schools and universities in Kuwait are segregated due to Islamic traditions, as well as governing how a woman acts in a society. "The women's situation often is evaluated, mainly if not exclusively, in light of the religious injunctions and traditional norms that govern the female condition" (Longva A, 1993).

The English language, which has been taught in Kuwait since 1993, was and is not accepted by some to be spoken publicly especially since it has no connection to Kuwait's culture or religion. Those that spoke English more than Arabic were labelled as 'westernized' or as 'chicken nuggets,' and were criticised and seen as Kuwaiti citizens that are losing their 'Kuwaitiness' "which describes as 'our language', 'our culture' and 'our religion" (AlNakib, 2012). The English language is seen as "powerful and prestigious but is also seen as the diffuser of foreign cultures, values, and interests" (Malallah, 2000). Whereas one study in Saudi Arabia showed that English was not seen as a negative tool nor a threat to their culture (Alam, Hussain, and Khan, 1988).

\subsection{The Effects of COVID-19 on Education in Kuwait}

The spread of the COVID-19 pandemic led to changes in the educational system in Kuwait. On March 12, 2020, the Ministry of Education suspended all government sectors, including public schools, and students' education was put on hold until further notice (Alhouti, 2020). Students subsequently did not attend classes till August $9^{\text {th }}, 2020$. Furthermore, public schools and universities switched to teaching via online platforms such as Microsoft Teams.

Teachers were required to take online training courses to learn how to teach their students online for the upcoming semesters. As of the date of this article, all school classes are taught online, and students are not allowed to be on university or school premises for any purpose. 


\section{Teaching Students Online}

The idea of teaching online was a stressful issue for several teachers that had never done it before, since teaching students in a classroom is completely different from teaching online. One obvious factor is the setting. Another factor is observing students' facial expressions when one is teaching. In class, a teacher can read a student's face to determine whether the student is understanding the lesson or is not paying attention. Small factors such as these affect the way a teacher must adapt to teaching online; teachers have to figure out other ways to see if their students are paying attention or whether they are understanding the lesson.

Another factor is that students can now hide behind a screen knowing that participation is not mandatory even when called upon.

This issue of decreased participation made the authors question how students will learn if they do not share their answers and learn from their errors or mistakes. This led us to ask ourselves whether one of the factors that is stopping them from participating might be that they are afraid of making errors or mistakes. We therefore created a questionnaire to investigate why they avoid situations where they might make errors or mistakes.

\section{The Difference Between Errors and Mistakes}

The two terms, error and mistake, are often seen as synonymous. However, some linguists have distinguished differences between the two. Pit Corder, who is well known for his contribution to the study of error analysis, argued that errors are deviances that cannot be self-corrected and need more information or feedback in order to fix them, whereas when the learner knows how "to correct a fault in his or her output, it is assumed that the form he or she selected was not the one he [or she] intended, and we shall say that the fault is a mistake" and can be self-corrected (as cited in James, 1998).

\section{The Importance of Making Mistakes in Learning a New Language}

As infants learn a language, they practice using words to express themselves. Parents help the infant by giving them feedback if something is said incorrectly. The infant then corrects his or her output. It is a simple and crucial process of learning a language, and parents often do not realize the impact of these small steps in the baby's language learning process. "As infants interact with objects and people, they generate rich perceptual and social feedback that paves the way for learning language" (Tamis-LeMonda, Catherine \& Kuchirko, Yana \& Suh, Daniel, 2018). Figure 2 shows the stages in this process, as well as the natural way of correcting an error or mistake. 


\section{Figure 2}

The Natural Language Learning Stages in Making a Mistake or an Error

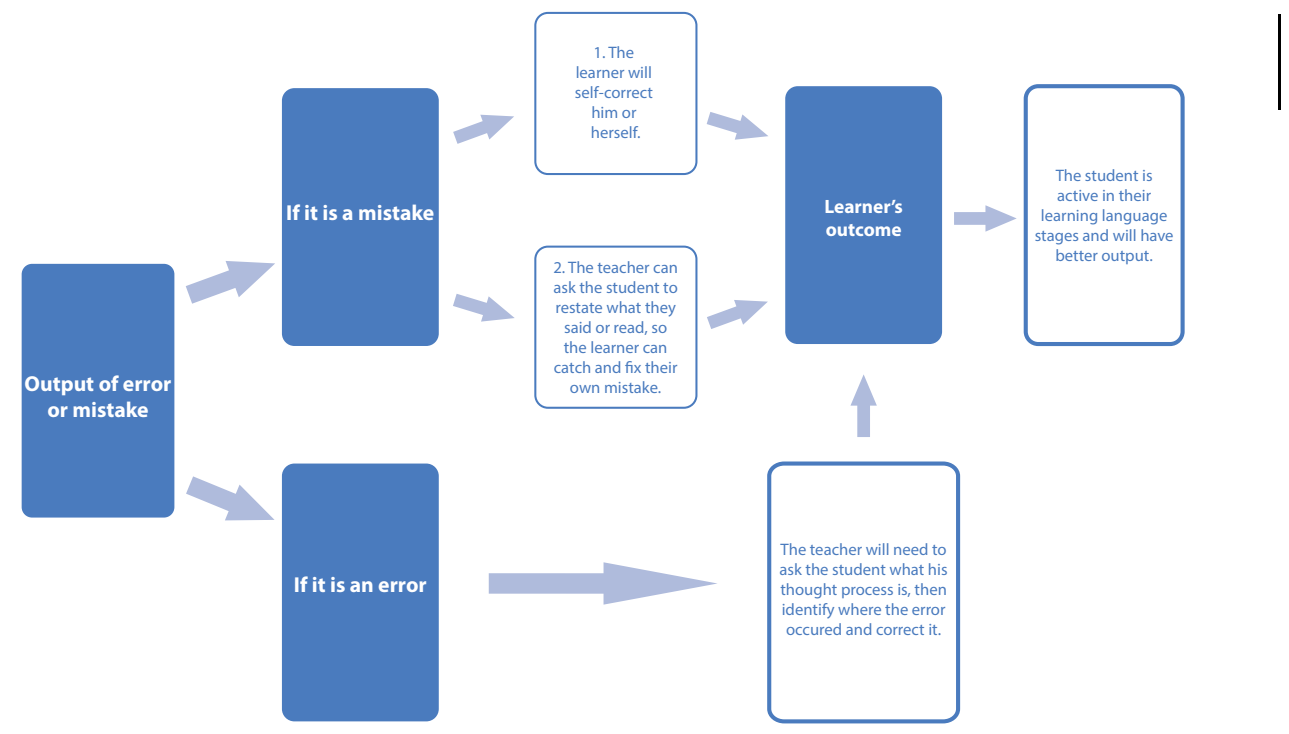

In this study, we will focus on the process of making mistakes, as opposed to errors, and the steps that need to be taken to foster students' learning process. We decided to focus on the issue of students making mistakes because that is where we think the problem lies. The transition between their making a mistake and correcting themselves is crucial and fragile. This particular stage is perhaps where the reason for students' unwilling to communicate in English may be found. Something may have happened in their previous English classes that led them to avoid communicating in English.

A further reason why we decided to focus on mistakes rather than errors was because we saw students repeat the same mistakes without learning from them, and this is an area where the students' should be actively participating in their learning process. Students need to learn from their mistakes in order to avoid making the same mistake in the future. A teacher should help students recognize their mistakes by guiding them to do so.

\section{Research Questions}


1. What role does dealing with mistakes play in Kuwaiti students' unwillingness to communicate in English?

2. Why are students afraid of making mistakes in their English classroom?

\section{Methodology}

\subsection{Participants}

Two hundred and twenty-one female Kuwaiti undergraduate students from the College of Basic Education (CBE) at the Public Authority for Applied Education and Training (PAAET) participated in completing a questionnaire. PAAET is a segregated university that does not allow male and female students to be taught in the same class. Hence, the questionnaire was given to female students only.

The participants were studying to become teachers, but none of them were studying to be English teachers. The age of the participants ranged from 18 to 45 . Approximately $57 \%$ of the participants fell under the age of $20-25,30 \%$ were $17-19,5 \%$ were $26-30,5 \%$ were $31-36$, and only $2.7 \%$ were 37-45. All of the participants were Arab Muslims.

All of the participants were taking the English foundation class, which contributes no credits to their GPA. To pass this class, students must earn $60 \%$ or above. Also, this class is taken when students have failed to pass the English proficiency test at PAAET, or did not take the exam.

Students were informed that they were going to receive a questionnaire that required their input, and that this was not a graded assignment.

\subsection{Instrument and Data Collection}

The questionnaire was given to students through the Microsoft Teams platform using Google Forms. The questionnaire contained was two sections, 18 questions with only one answer to be chosen, and it was written in both English and Arabic to ensure that students understood each question. The questionnaire was given to two classes that were taught by one of the authors. One class had 115 students and the other had 106 students. Classes during the pandemic were taught online only, and the questionnaire was given to the students during online class hours during the first week of the semester.

After everyone had submitted their questionnaires, some students expressed a wish to share their personal experiences with teachers who had made them feel embarrassed while they were in elementary, middle, or high 
school. Once one student shared her experience, it led to several more students wanting to share their personal experiences.

\subsection{Data Analysis}

Data were cleaned and coded in MS Excel before being transferred to IBM SPSS v25.0 for analysis. We started with descriptive statistics and then ran a series of chi-square tests to answer the research questions.

\section{Study Results}

\subsection{Participant demographics}

Table 1 shows the characteristics of participants to determine the factors that create fear of making verbal mistakes, we examined the role of factors such as demographics (age and area of residence (governate)), norms (cultural, religious, and family traditions), mode of learning (online vs in a physical classroom) and previous experience of teachers' negative feedback.

$12 \%$ of respondents lived in Asmaa, 5\% in Hawallii, $25 \%$ in Mubarak Al Kabeer, 26\% in Jahra, 22\% in Farwaniya, and 10\% in Ahmedi. Most of the respondents (93\%) had attended a public school, and only $6 \%$ had attended a private school. Among the respondents, about $61 \%$ expressed a preference for the online mode of learning, whereas 39\% preferred to learn in a classroom environment. Moreover, when asked about their general attitude toward the English language, the majority of the respondents (67\%) said that they liked English classes.

\section{Table 1}

Demographic Characteristics of Participants

\begin{tabular}{lll}
\hline \multirow{2}{*}{ Factor } & Distribution $(\mathbf{N}=\mathbf{2 1 9})$ & \\
\cline { 2 - 3 } & Frequency & Percentage \\
\hline Age & 65 & \\
$17-19$ & 126 & 29,7 \\
$20-25$ & 11 & 57,5 \\
$26-30$ & 11 & 5,0 \\
$31-36$ & 6 & 5,0 \\
$37-45$ & & 2,7 \\
& & \\
\hline Governate & 27 & 12,4 \\
Asmaa & 12 & 5,5 \\
Hawallii & 55 & 25,2 \\
Mubarak Al Kabeer & 5
\end{tabular}




\begin{tabular}{cll}
\hline Jahra & 56 & 25,7 \\
Farwaniya & 47 & 21,6 \\
Ahmedi & 21 & 9,6 \\
& & \\
\hline $\begin{array}{c}\text { Type of } \quad \text { School } \\
\text { Attended }\end{array}$ & 205 & 93,6 \\
Public & 14 & 6,4 \\
Private & & \\
Missing & & \\
Prefer Mode of & 133 & 60,7 \\
Learning & 86 & 39,3 \\
Online & & \\
In a classroom & 146 & 66,7 \\
Attitude $\quad$ toward & & 33,3 \\
English Classes & 73 & \\
Liked & & \\
Did not like &
\end{tabular}

\subsection{Intrinsic factors}

Respondents were asked a series of questions to determine their attitude towards making mistakes. Firstly, they were asked whether they thought that they learned from their mistakes. Almost all the respondents (99\%) felt that they did indeed learn from their mistakes. However, when asked if they were afraid of making verbal mistakes in front of their peers and teachers, a little over $50 \%$ of the respondents responded that they were. Figure 3 shows the respondents' opinions in percentages. Further, an application of the chi-square test showed that those who were afraid of making mistakes in front of classmates were also afraid of doing so in front of their teachers $[X 2(1,219)=49.476, p<0.05, v=0.475]$.

\section{Figure 3}

Attitude Towards Making Mistakes Per Context (in percentages)

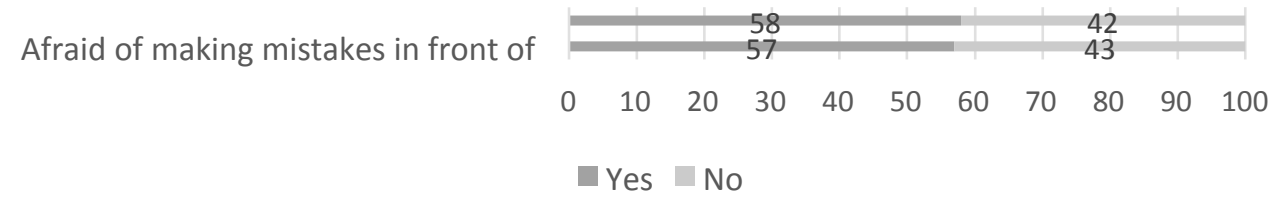


Figure 4 extends this data by showing reasons given by participants for being reluctant to make mistakes in front of their peers and teachers.

\section{Figure 4}

\section{Reasons for Being Afraid of Making Mistakes}

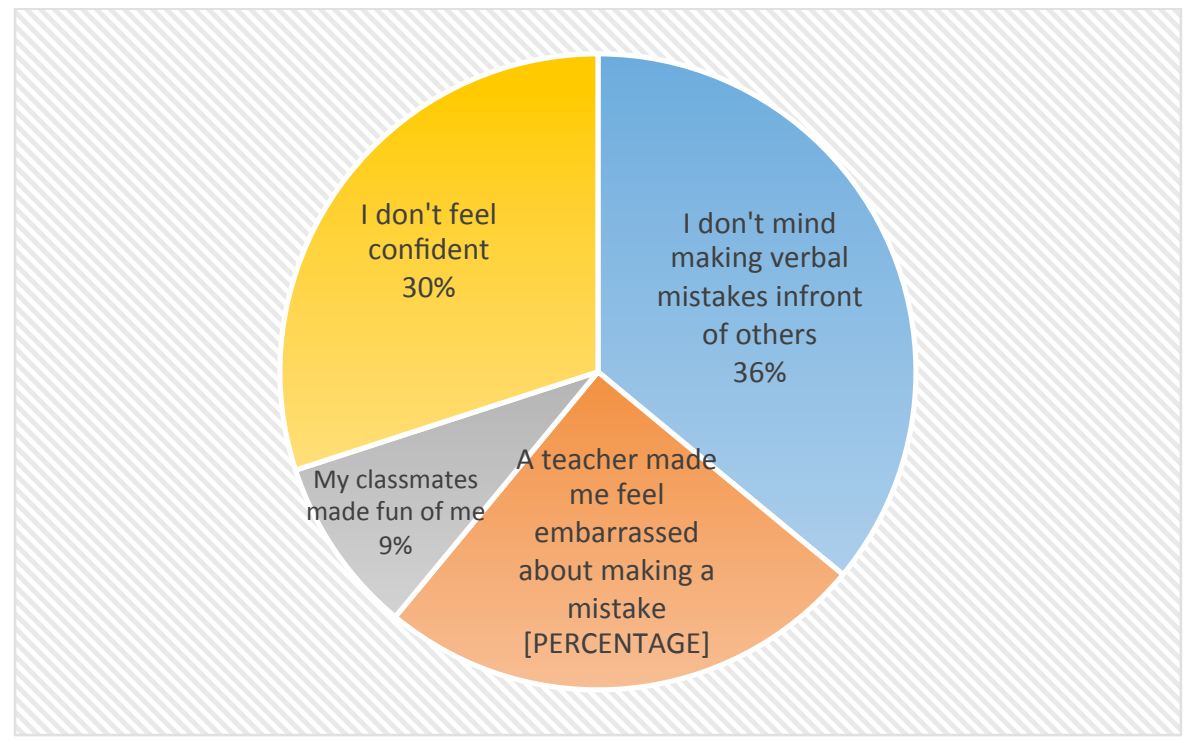

$30 \%$ of the respondents mentioned that they felt uncomfortable making verbal mistakes because they did not feel confident; $25 \%$ mentioned that they had had an experience where their teachers made them feel embarrassed about making a mistake; and only $9 \%$ attributed their fear to peers having previously made fun of them for their mistakes.

\subsubsection{Age}

Figure 5 shows the distribution of age with regard to whether respondents were afraid of making mistakes in front of classmates. As shown in the figure, although the majority of respondents in each group were afraid of making mistakes in front of classmates, the groups did not differ significantly $[X 2(4, N=219)=3.718, p=0.44]$

\section{Figure 5}

Age Distribution of Respondents Afraid of Making Mistakes in Front of Classmates 


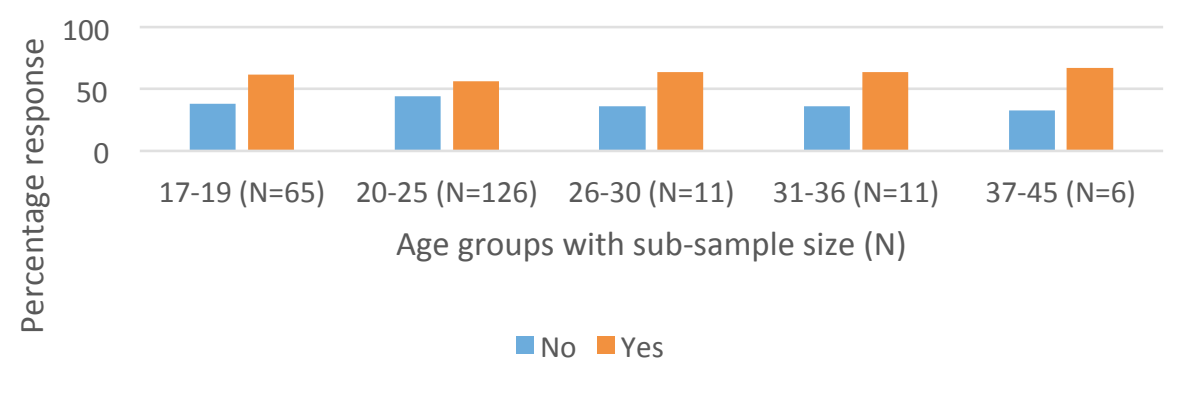

Figure 6 shows the distribution of age with regard to whether respondents were afraid of making mistakes in front of teachers. As shown in the figure, the majority in each group were afraid of making mistakes in front of teachers, but the groups did not differ significantly $[X 2(4, N=219)=1.10$, $p=0.89]$

\section{Figure 6}

Age Frequency Distribution of Respondents Afraid of Making Mistakes in Front of Teachers

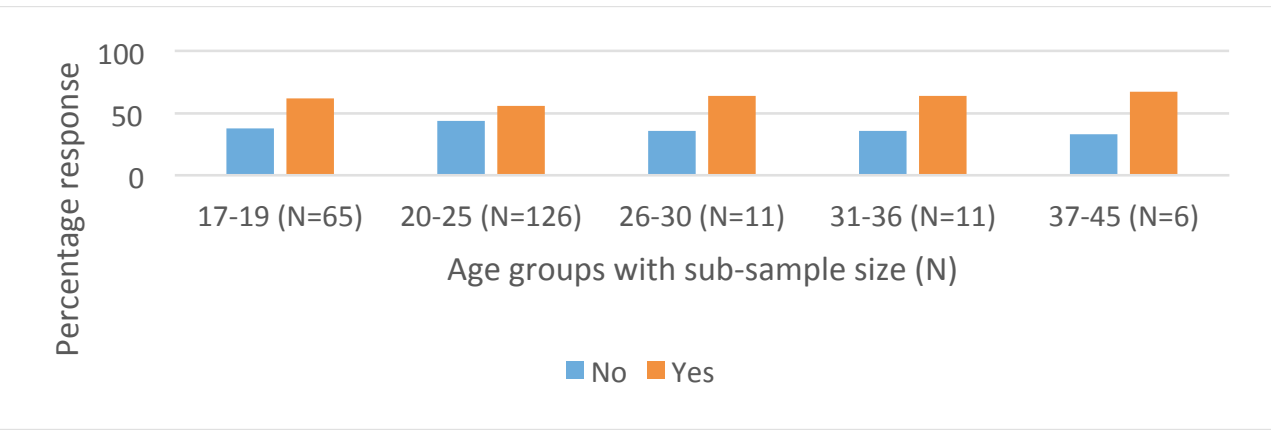

Therefore, we can conclude that age does not predict whether a student will be afraid to make a mistake in front of his/her classmates and/or teachers.

\subsubsection{Governate/Area of Residence}

Figure 7 shows the percentage distribution per governate with regard to whether respondents were afraid of making mistakes in front of classmates. As shown in the figure, the majority of respondents in each area were afraid of making mistakes in front of classmates. However, the groups did not differ significantly $[X 2(5, N=218)=1.627, p=0.89]$ 


\section{Figure 7}

Distribution per Governate of Respondents Afraid of Making Mistakes in Front of Classmates

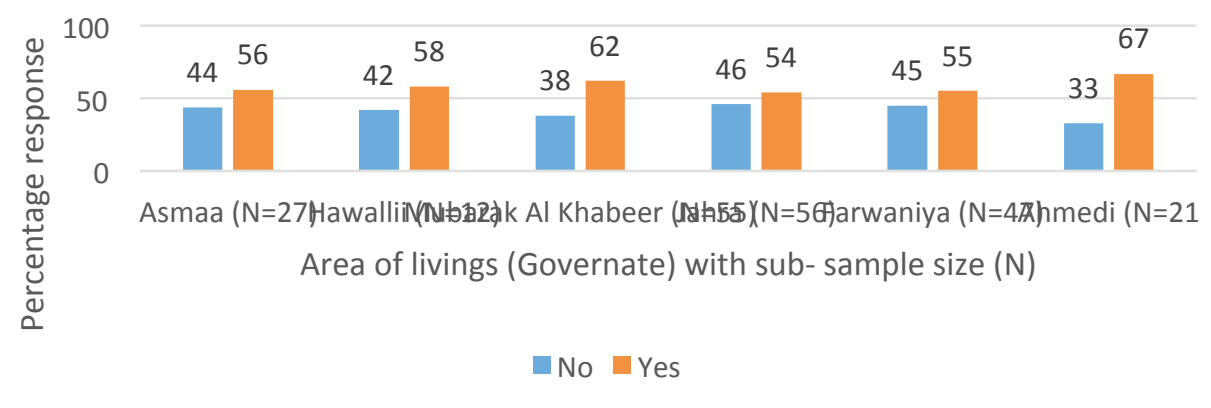

Figure 8 shows the percentage distribution per governate with regard to whether respondents were afraid of making a mistake in front of teachers. As shown in the figure, the majority of respondents in each area were afraid of making mistakes in front of teachers. However, the groups did not differ significantly $[X 2(5, N=218)=3.43, p=0.63]$

\section{Figure 8}

Distribution per Governate of Respondents Afraid of Making Mistakes in Front of Teachers

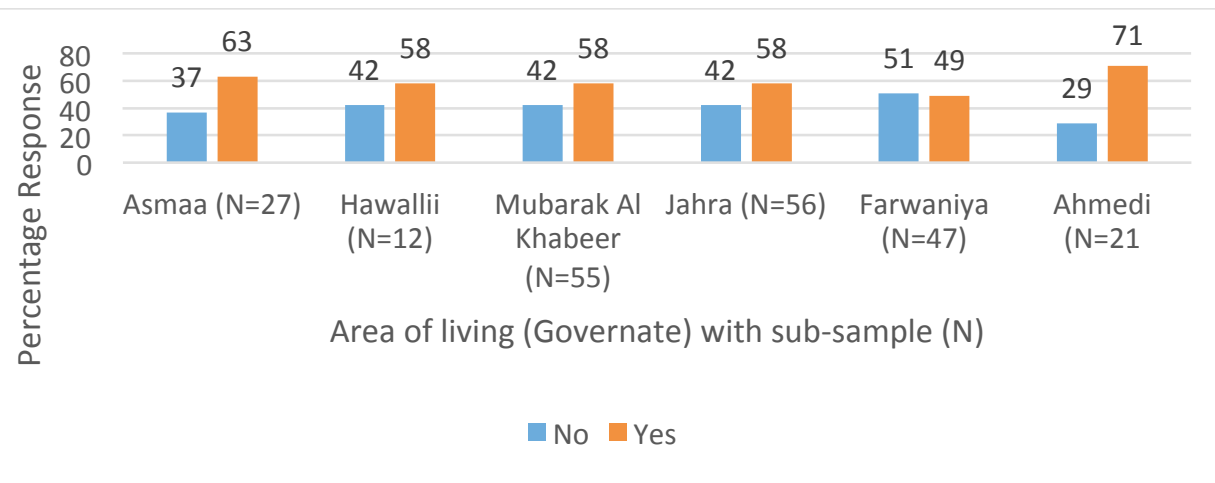

Therefore, we can conclude that area of residence does not predict whether a person will be afraid to make a mistake in front of his/her classmates and teachers. 


\subsubsection{Impact of Norms}

Respondents were asked a series of questions to investigate how elements of their environment (social, cultural, and religious norms) might influence their attitude towards making mistakes.

Firstly, the extent to which gender played a role was explored.

\section{Figure 9}

\section{Views on Norms Regarding Making Mistakes}

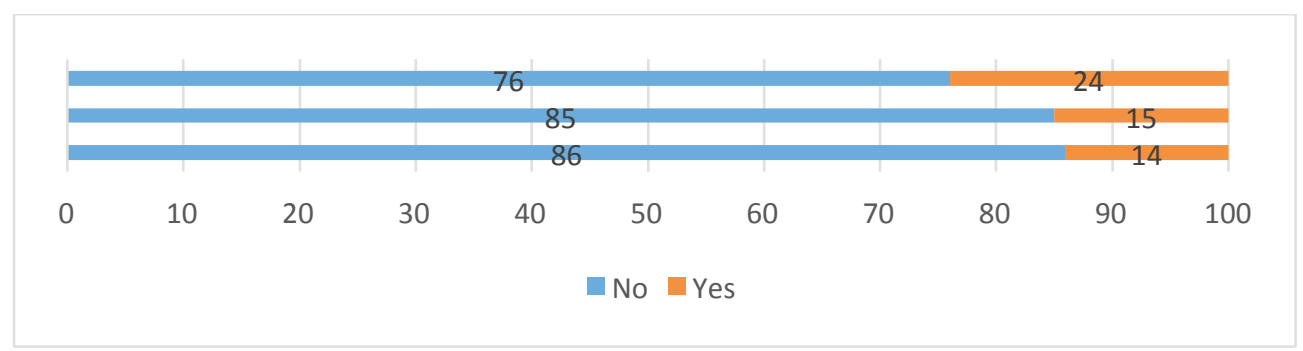

As shown in Figure 9, a large proportion of respondents $(85 \%$ and $86 \%$ respectively) believed that in their culture and religion, making mistakes as a girl is not unacceptable. Further, two-thirds (76\%) of respondents also believed that it is not unacceptable in their family traditions for a girl to make mistakes. Figure 9 also indicates that in the view of most of the respondents, in their culture, religion and family tradition, there was no rejection of the notion of females making mistakes.

Table 2 shows the cross-tabulation of respondents' opinions regarding the role of gender in generating fear of making mistakes in front of classmates. No significant difference was found between the respondents who felt it was not unacceptable in their culture/religion/family tradition for girls to make mistakes in front of classmates, and those who felt that it was.

\section{Table 2}

The Role of Gender in Generating Fear of Making Mistakes in Front of Classmates 


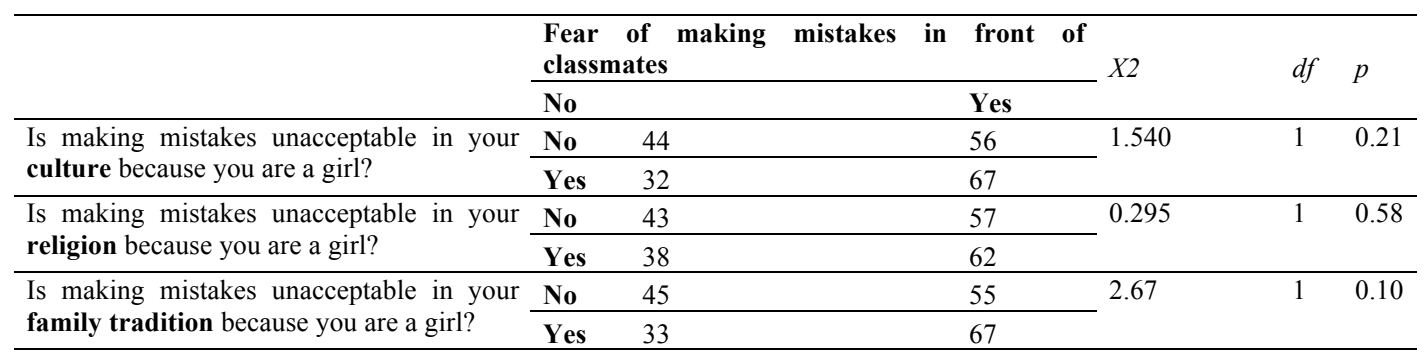

Table 3 shows the cross-tabulation of respondents' opinions regarding the role of cultural norms in generating fear of making mistakes in front of teachers. No significant difference was found between the respondents who felt it was not unacceptable in their culture/religion/family tradition to make mistakes in front of teachers, and those who felt that it was.

\section{Table 3}

The Role of Cultural Norms in Generating Fear of Making Mistakes in Front of a Teacher

\begin{tabular}{|c|c|c|c|c|c|c|}
\hline & & \multicolumn{2}{|c|}{$\begin{array}{l}\text { Fear of making mistakes in front } \\
\text { of teachers }\end{array}$} & \multirow[t]{2}{*}{$X 2$} & \multirow[t]{2}{*}{$d f$} & \multirow{2}{*}{$p$} \\
\hline & & No & Yes & & & \\
\hline \multirow{2}{*}{$\begin{array}{l}\text { Is making mistakes unacceptable in } \\
\text { your culture because you are a girl? }\end{array}$} & No & 43 & 57 & \multirow[t]{2}{*}{0.548} & \multirow[t]{2}{*}{1} & \multirow[t]{2}{*}{0.46} \\
\hline & Yes & 36 & 64 & & & \\
\hline \multirow{2}{*}{$\begin{array}{l}\text { Is making mistakes unacceptable in } \\
\text { your religion because you are a girl? }\end{array}$} & No & 43 & 57 & \multirow[t]{2}{*}{0.649} & \multirow[t]{2}{*}{1} & \multirow[t]{2}{*}{0.42} \\
\hline & Yes & 35 & 65 & & & \\
\hline \multirow{2}{*}{$\begin{array}{l}\text { Is making mistakes unacceptable in } \\
\text { your family tradition because you } \\
\text { are a girl? }\end{array}$} & No & 44 & 56 & \multirow[t]{2}{*}{2.204} & \multirow[t]{2}{*}{1} & \multirow[t]{2}{*}{0.13} \\
\hline & Yes & 33 & 67 & & & \\
\hline
\end{tabular}

\subsubsection{Mode of Learning}

We further inquired about participants' level of comfort in making mistakes in an online class compared to in a physical classroom.

Table 1 (above) showed that about $61 \%$ of respondents preferred online learning. To investigate whether the mode of learning affected their attitude towards making mistakes, we compared those who preferred online learning with those who preferred learning in a physical classroom. The results are shown in Table 4 and Table 5. 


\section{Table 4}

The Role of Mode of Learning in Generating Fear of Making Mistakes in Front of Classmates

\begin{tabular}{|c|c|c|c|c|c|}
\hline \multirow[t]{2}{*}{ Mode of Learning } & \multicolumn{2}{|c|}{ Fear of making mistakes in front of classmates } & \multirow{2}{*}{$X 2$} & \multirow{2}{*}{$d f$} & \multirow[b]{2}{*}{$p$} \\
\hline & No & Yes & & & \\
\hline Online & 41 & 59 & 0.482 & 1 & 0.49 \\
\hline In Classroom & & 55 & & & \\
\hline
\end{tabular}

\section{Table 5}

The Role of Mode of Learning in Generating Fear of Making Mistakes in Front of Teachers

\begin{tabular}{|c|c|c|c|c|c|}
\hline \multirow[t]{2}{*}{ Mode of Learning } & \multicolumn{2}{|c|}{ Fear of making mistakes in front of teachers } & \multirow{2}{*}{$X 2$} & \multirow{2}{*}{$d f$} & \multirow{2}{*}{$p$} \\
\hline & No & Yes & & & \\
\hline Online & 44 & 56 & 1.100 & 1 & 0.29 \\
\hline In Classroom & 37 & 63 & & & \\
\hline
\end{tabular}

From Tables 4 and 5, it is evident that the mode of learning does not affect the fear of making a mistake.

\subsubsection{Previous experience with teachers}

A further series of questions explored the teacher's role in shaping students' attitude towards making mistakes. Firstly, we asked if teachers had ridiculed them for making mistakes in the past. $40 \%$ of the study participants responded that they had had such an experience. Secondly, we asked whether they would be less afraid of making mistakes if the teacher gave encouragement when this occurred. $71 \%$ of the respondents replied positively. Figure 10 shows participants' responses in percentages. 


\section{Figure 10}

Views Regarding Teacher's Attitude

Did a teacher embarrass you for

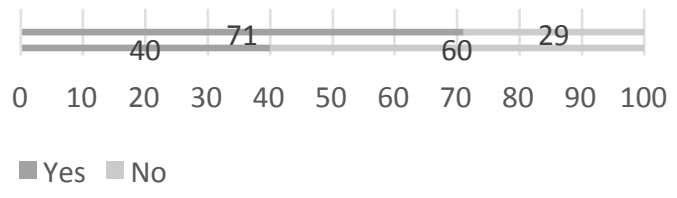

Furthermore, $57 \%$ of students were not scared of correcting their teachers' verbal mistakes.

As shown in Figure 10, 40\% of the respondents had been previously ridiculed by a teacher. To examine whether a negative prior experience with a teacher impacted fear of making mistakes, we ran a chi-square test. The results are shown in Tables 6 and 7.

\section{Table 6}

The Role of Previous Experience in Generating Fear of Making Mistakes in Front of Classmates

\begin{tabular}{|c|c|c|c|c|c|}
\hline \multirow{2}{*}{$\begin{array}{l}\text { Previous negative } \\
\text { experience with teacher }\end{array}$} & \multicolumn{2}{|c|}{ Fear of making mistakes in front of classmates } & \multirow{2}{*}{$X 2$} & \multirow{2}{*}{$d f$} & \multirow{2}{*}{$p$} \\
\hline & No & Yes & & & \\
\hline No & 51 & 49 & 10.052 & 1 & 0.002 \\
\hline Yes & 29 & 71 & & & \\
\hline
\end{tabular}

\section{Table 7}

The Role of Previous Experience in Generating Fear of Making Mistakes in Front of Teachers

\begin{tabular}{|c|c|c|c|c|c|}
\hline \multirow{2}{*}{$\begin{array}{l}\text { Previous negative } \\
\text { experience with teacher }\end{array}$} & \multicolumn{2}{|c|}{ Fear of making mistakes in front of teachers } & \multirow{2}{*}{$X 2$} & \multirow{2}{*}{$d f$} & \multirow{2}{*}{$p$} \\
\hline & No & Yes & & & \\
\hline No & 50 & 50 & 10.464 & 1 & 0.001 \\
\hline Yes & 28 & 72 & & & \\
\hline
\end{tabular}

Results in both Table 6 and 7 show a significant association between previous negative experiences of teachers' feedback and fear of making mistakes. The analysis shows that the students who had been ridiculed by a teacher for making a mistake in the past were afraid of making a mistake both in front of their classmates $(p<0.002)$ and in front of teachers $(p<0.001)$. 


\section{Discussion}

The English language has been taught in Kuwait as a second language since 1993. It has been added to the school curriculum as a mandatory subject, with the aim that Kuwaiti students should be bilingual once they graduate from school. However, Kuwaiti students' English proficiency level is ranked as low by the EF English Proficiency Index for Schools (EF English Proficiency Index for Schools , n.d.). The Arab Times Newspaper stated, "Kuwait ranked seventh in the Middle East out of 10 participating countries in the index compiled by First Education Foundation, and ... took 78th place out of 88 countries in 2018, and ranked 84 out of 100 countries in 2019 (Kuwait ranks 84 out of 100 countries in English proficiency index for 2019, 2019).

Furthermore, "there is a continuous complaint from the Ministry of Education in Kuwait that English major graduates from the English department at the CBE are generally below the standard" (Dashti, 2019).

The demand for learning English is more prominent than ever after the pandemic in Kuwait. As of August 2019, teachers are using Microsoft Teams and other learning platforms to teach English. However, CBE Kuwaiti pre-service teachers have low English proficiency.

With regard to Arab students' low proficiency, Alshaar (1994) argued that it is not related to linguistic factors, but rather, perhaps, to sociopolitical, educational, or socio-psychological factors. Therefore, it is important to look closely at the internal and external factors that might foster students' WTC.

After exploring the layers of WTC, we decided to look further into students' learning processes to identify the factors that hampered their progress. This includes motivation, which Othman and Shuqair (2013) argue is one of the" key factors that contribute to students successfully learning English".

Analysis of the data in this study indicated that external factors such as age, governate, mode of learning and religion did not have any noticeable influence. However, there was significant impact when it came to certain internal factors.

If we look at the results in this study, and specifically at Figure 4, $25 \%$ of the students who completed the questionnaire had been ridiculed by an English teacher in the past, and were thus not motivated to learn or try to share their answers during class. Figure 4 showed that $30 \%$ of students did not feel confident, $9 \%$ of students had been made fun of by their peers during class, and only $36 \%$ felt they were comfortable sharing their answers in the 
classroom. As a result, $36 \%$ percent of the students would be active, while the other $64 \%$ would be passive learners.

This study found that one of the most significant factors impeding WTC was fear of ridicule by a teacher. Figure 10 shows what happens when a students is ridiculed by a teacher if their output is either a mistake or an error; the student may develop a negative attitude towards the English language, and become a passive learner.

Another factor identified in the study is that $57 \%$ of students do not mind correcting their teacher when he or she pronounces words incorrectly. However, the remaining students that do not realize that the teacher pronounces words incorrectly will mimic the teacher's mistakes. This is a common situation in Kuwait, and we hear our students pronounce words incorrectly due to their teacher's first language interference. This is an issue that needs more investigation.

Another important factor to consider is the age at which learners in Kuwait start learning English. Ideally, according to Krashen's proposed Critical Period (Krashen, 1973), children should start learning English at the earliest possible age. However, although there are preschools in Kuwait, it is not mandatory that children enrol, and the decision is left to the parents. Enrolment in school becomes mandatory only when children enter the 1st grade, which would be at the age of 4 or 5 years old. By this time, children have almost passed the critical period that Stephan Krashen discussed.

These are only some of the suggested possibilities, but there might be more negative outcomes, and further investigation is needed. Ellis (2008) argues that "learners attitudes have an impact on the level of L2 proficiency achieved by individual learners and are themselves influenced by this success."

\section{Conclusion}

Teachers have a significant effect on their students' learning process, which they need to foster. They need to be aware of their teaching methods and the role they play. It would be beneficial if teachers were to learn more about the internal and external factors influencing WTC and be aware that students are afraid to practice speaking English due to past experiences. As a result, teachers would be more sympathetic to their students, and avoid the negative practice of ridiculing them. Ridicule can affect students' attitude, which leads to loss of motivation to learn, and reluctance to practice their speaking skills in the classroom.

It would also be beneficial for teachers to understand the differences between errors and mistakes. This would allow them to adopt the appropriate approach depending on whether a student utters a mistake or an error. It is 
possible that many teachers do not distinguish between the two, and that therefore, students are often not active in their learning, or are not learning from their mistakes.

With regard to the issue of English education policy, the Ministry of Education may need to consider starting education before the age of 5 and making preschool mandatory. As Stephan Krashen elaborated in his study, the critical period for learning is from early childhood. Not going to school until they are 4 or 5 can delay children's language development and lose the chance to develop the language like a native speaker.

There are several other variables that may contribute to students' outcomes that were not investigated or discussed in this research. Further research is needed to determine why Kuwaiti students' English proficiency is low.

\section{Appendix}

1. Are you afraid of making mistakes in front of your classmates?
a. Yes
b. No

2. Are you afraid of making verbal mistakes in front of your teacher?
a. Yes
b. No

3. Do you feel comfortable making verbal mistakes online?
a. Yes
b. No

4. Do you feel comfortable making verbal mistakes in a classroom?
a. Yes
b. No

5. Do you feel uncomfortable making mistakes because:
a. A teacher made me feel embarrassed about making mistake (in the past)
b. My classmates made fun of me.
c. I don't feel confident.
d. I don't mind making verbal mistakes in front of others.

6. Do you think if the teacher encouraged making mistakes then you would not mind making mistakes as well?
a. Yes 

b. No

7. Do you think you learn from your mistakes?
a. Yes
b. No

8. Is making mistakes unacceptable in your culture because you are a girl?
a. Yes
b. No

9. Is making mistakes unacceptable in your religion because you are a girl?
a. Yes
b. No

10. Is making mistakes unacceptable in your family tradition because you are a girl?
a. Yes
b. No

11. How old are you?

e.a. Between 17-19

d.b.Between 20-25

e.c. Between 26-30

f.d. Between 31-36

g.e. Between 37-45

f. Above 46

12. Which governate do you live in?

\author{
h.a. Asma \\ i.b. Hawallii \\ j.c. Mubarak Al Kabeer \\ k.d.Jahra \\ 1.e. Farwaniya \\ f. Ahmedi
}

11.13. Which type of school did you attend?
a. Private school
b. Public school 
12.14. Do you like your English classes?

a. Yes

b. No

13.15. If your teacher made a mistake are you scared to correct her/him?
a. Yes
b. No

14.16. Did your teacher embarrass you when you made a mistake in the past?
a. Yes
b. No

15.17. If your teacher said it is ok to make verbal mistakes and you learn from your mistakes, would you:

a. Not want to make mistakes in front of your classmates.

b. Not want to makes mistakes front of your teacher.

c. Feel comfortable and do not mind about making mistakes.

d. Not answer because I am shy person in general.

16.18. Do you prefer learning:

a. Online

b. In a classroom

\section{References:}

Alam, M.A., Hussain, S.M. and Khan, B.A. (1988) A Study of the Attitudes of Students, Teachers and Parents Towards English as a Foreign Language in Saudi Arabian Public Schools. Saudi Arabia, Ministry of Education, Educational Development, The General Directorate of Research \& Evaluation.

Al Darwish, S., \& Sadeqi, A. (2016). reasons for college students to plagiarize in EFL writing: Students' motivation to pass. International Education Studies, 99-110.

Al-Nakib, Rania (2012). Dialogic universalism and human rights education: A case study in Kuwait. [Doctoral dissertation, Institute of Education]. University of London. 
Al-Nouri, R. M. (2019). Why are Kuwaiti students weak in the English language? Mult-Knowledge Electronic Comprehensive Journal for Education and Science Publication (25).

Alhouti, I. (2020). Education during the pandemic: The case of Kuwait. Journal of Professional Capital and Community, 5(3/4), 213-225. https://doi.org/10.1108/JPCC-06-2020-0050

Alshaar, B. E. (1997). Attitudes and motivation of second language learners in Kuwait. Retrospective Theses and Dissertations. 277. http://lib.dr.iastate.edu/rtd/277

Benraghda, A., Radzuan, R., \& Benrraghda, A. (2017). Factors that affect Arab EFL learners' English pronunciation. English for Specific Purposes World, 1(53):13.

Brown, H. D. (2007). Principles of language learning and teaching. $\left(5^{\text {th }} \mathrm{ed}\right)$. NY: Pearson Longman.

Bukhari, S., Cheng, X., \& Khan, S. (2015). Willingness to communicate in English as a second language: A case study of Pakistani undergraduates. Journal of Education and Practice, 6(29), 39-44.

Burgoon, J. (1976). The unwillingness to communicate scale: Development and validation. Communication Monographs, 43(1). https://doi.org/10.1080/03637757609375916

Dashti, A. A. (2019). Investigating students' and staff members' attitudes toward the efficiency of the language skills: Modules offered during the Foundation Year. English Language Teaching, 12 (6), 24-32 .

EF English Proficiency Index for Schools. (2020). https://www.ef.com/wwen/epi/

Ellis, R. (1195). The study of second language acquisition. (3rd ed.). Oxford: Oxford University Press.

Halimi, F., Daniel, C., \& Alshammari, I. (2020). The manifestation of English learning anxiety in Kuwait ESL classrooms and its effective reduction. Journal of Classroom Interaction. 54(1), 60-76.

James, C. (1998). Errors in language learning and use: Exploring error analysis. Edinburgh: Harlow.

Krashen, S. (1973). Lateralization, language learning, and the critical period: Some new evidence. Language Learning, 23, 63-74. https://doi.org/10.1111/j.1467-1770.1973.tb00097.x

Kuwait ranks 84 out of 100 countries in English proficiency index for 2019. (2019, December 29). Arab Times. https://www.arabtimesonline.com/news/kuwait-ranks-84-out-of-100countries-in-english-proficiency-index-for-2019/

Longva, A. (1993). Kuwaiti Women at a Crossroads: Privileged Development and the Constraints of Ethnic Stratification. International Journal of 
Middle East Studies, 25(3), 443-456. Retrieved April 15, 2021, from http://www.jstor.org/stable/163954

MacIntyre, P., Clement, R., Dornyei, Z., \& Noels, K. (1998). Conceptualizing willingness to communicate in a L2: A situational model of L2 confidence and affiliation. The Modern Language Journal, $82(4)$, $545-562$. https://www.researchgate.net/deref/http $\% 3 \mathrm{~A} \% 2 \mathrm{~F} \% 2 \mathrm{Fdx}$.doi.org\%2F 10.1111\%2Fj.1540-4781.1998.tb05543.x

Malallah, Seham (2000) English in an Arabic Environment: Current Attitudes to English among Kuwait University Students, International Journal of Bilingual Education and Bilingualism, 3:1, 19-43, DOI: 10.1080/13670050008667698

McCroskey, J., \& Baer, J. (1985). Willingness to communicate: The construct and its measurement. [Washington, D.C.] : Distributed by ERIC Clearinghouse, https://eric.ed.gov/?id=ED265604

Othman, D., \& Shuqair, D. (2013). The impact of motivation on English language. International Journal of Higher Education, 2(4), 123-130.

Oxford, R. (1990). Language learning strategies: What every teacher should know. New York: Newbury House.

Rashed, M. S. (2017). Why do Kuwaiti students in the College of Arts think that learning English is both difficult and unnecessary? European Journal of English Language Teaching, 2(3), 68-82. http://dx.doi.org/10.5281/zenodo.809478

Shumin, K. (2012). Factors to consider: developing adult EFL students' speaking abilities. In J. Richards, \& W. Renandya, Methodolgy in Language Teaching: An Anthology of Current Practice (pp. 204211). NY: Cambridge University Press.

Tamis-LeMonda, Catherine \& Kuchirko, Yana \& Suh, Daniel. (2018). Taking Center Stage: Infants' Active Role In Language Learning. 10.1007/978-3-319-77182-3 3.

Tuan, N. H., \& Mai, T. N. (2015). Factors affecting students' speaking performance at Le Thanh Hien High School. Asian Journal of Educational Research, 3(2), 8-23. http://www.multidisciplinaryjournals.com/wpcontent/uploads/2015/03/FACTORS-AFFECTINGSTUDENTS\%E2\%80\%99-SPEAKING.pdf

Wahidah, F. S. (2016). Students' speaking problems and factors causing it, $X V I(1)$. http://www.e-journal.unswagati-crb.ac.id/ 